\title{
S-BASED TAXATION UNDER DEFAULT RISK
}

\author{
PAOLO M. PANTEGHINI
}

CESIFO WORKING PAPER NO. 1496

CAtegory 1: Public Finance

JULY 2005

An electronic version of the paper may be downloaded

- from the SSRN website:

www.SSRN.com

- from the CESifo website:

www.CESifo.de 


\title{
S-BASED TAXATION UNDER DEFAULT Risk
}

\begin{abstract}
This article studies the characteristics of a S-based tax system under default risk. In particular we show that its neutrality properties depend on whether debt is protected or unprotected. In the former case, this system is neutral. In the latter case, where default timing is optimally chosen by shareholders, the S-based system is neutral with respect to real decisions only if the firm's and the lender's tax rate are equal. However, the shareholders' decision to default is always distorted.
\end{abstract}

JEL Code: H25, H32.

Keywords: capital structure, corporate taxation, neutrality, option pricing.

\author{
Paolo M. Panteghini \\ University of Brescia \\ Via San Faustino 74/b \\ Brescia 25122 \\ Italy \\ panteghi@eco.unibs.it
}

The author would like to thank Domenico Cuoco, Vesa Kanniainen, Francesco Menoncin, Michele Moretto, and Carlo Scarpa for helpful comments on earlier drafts. Usual disclaimers hold. 


\section{Introduction}

One of the basic neutral tax designs is the 'imputed income method' (see Boadway and Bruce, 1984). Over the last decade this method has become popular in Europe. At the beginning of the '90s, the Nordic countries introduced Dual Income Tax (DIT) which allows a lower tax rate on capital income. In the same period, the IFS Capital Taxes Group (1991) proposed the Allowance for Corporate Equity (ACE) and subsequently other countries, such as Austria, Croatia and Italy, applied dual tax systems. ${ }^{1}$ More recently, the Skauge Committee has proposed in Norway a tax system which shares some important features with the ACE tax system. ${ }^{2}$

The imputed income system allows two alternative treatments of the cost of debt. On the one hand, debt is deductible at the risk-free rate: this system will be named R-based. On the other hand, debt is deductible at the interest rate actually paid: we will call it the S-based system ${ }^{3}$. This option, which is quite common in existing tax systems, is supported by Keen and King (2002). They stress the fact that the computation of the tax base is easy as it is based on book values. Moreover they argue that the deduction of actual interest expenses does not distort firms' choices as long as debt is competitively supplied. In this case all rents accrue to shareholders, and taxation is neutral. This point is proven by Bond and Devereux (2003) (hereafter BD), who show that an S-based system is neutral under default risk even if the firm's and the lender's tax rate are different ${ }^{4}$. However, BD point out that their result holds on condition that capital markets are perfectly efficient and information is symmetric. If, instead, capital markets are imperfect and in particular information is asymmetric, borrowers and lenders might collude in order to avoid taxation. In this case, the government

\footnotetext{
${ }^{1}$ For further details see e.g. Bordignon et al. (2001), Cnossen (2005), Fehr and Wiegard (2001), Keen and King (2002), Keen (2003) and Zodrow (2003).

${ }^{2}$ The Norwegian proposal entails the introduction of a Rate-of-Return Allowance (RRA) at the level of domestic personal shareholders, rather than at the corporate level. The RRA is calculated as the risk-free interest rate multiplied by the basis of the share (see S $\phi$ rensen, 2003).

${ }^{3}$ For a comparison between the S-based and the R-based system see Becker and Fuest (2005).

${ }^{4}$ This property makes dual systems attractive at least in a closed economy (see Bond, 2000). As recently proven by Panteghini (2004), however, the imputed method can be attractive even in an open economy if multinational firms can decide not only whether but also when to invest.
} 
would require a greater amount of information to fight tax avoidance.

In this article we aim to show that the neutrality properties of the S-based system are less general than thought, and that distortions may arise even under perfect credit market efficiency and symmetric information. To show this we will depart from BD, who treat default as an exogenous event, and introduce two well-known default conditions. The first one refers to protected debt. In this case default may be triggered when the firms' asset value falls to the debt's value. This means that debt is approximated with a positive net-covenant. ${ }^{5}$ The second default condition regards unprotected debt, and implies that default timing is optimally chosen by shareholders. When the firm's net cash flow is negative, shareholders may have the opportunity to inject further equity capital in order to meet the firm's debt obligations. As long as they issue new capital and pay the interest rate they can exploit future recoveries in the firm's profitability. In this case, shareholders behave as if they owned a put option, whose exercise leads to default. ${ }^{6}$ It will be shown that neutrality holds only under fully protected debt financing. If, instead, debt is unprotected, a twofold distortion may arise. Firstly, investment may be distorted unless a uniform tax rate is levied on both shareholders and the lender. Secondly, taxation always affects shareholders' decision to default.

The article is structured as follows. Section 2 introduces a continuoustime model and analyzes both protected and unprotected debt. Section 3 describes the effects of S-based taxation on the firm's value. Section 4 derives the neutrality results under protected and unprotected debt financing. Section 5 summarizes the results and discusses their policy implications.

\section{The model}

In line with Leland (1994) we apply a continuous-time model describing the investment decision made by a representative firm. At time 0 , the firm decides whether to undertake an infinitely-lived project, whose cost is $I$ : investment is thus undertaken if the project Net Present Value is positive. ${ }^{7}$

\footnotetext{
${ }^{5}$ For further details see Brennan and Schwartz (1978), and Smith and Wardner (1977).

${ }^{6}$ As pointed out by Leland (1994) both protected and unprotected debt are widely used. In particular, minimum net-worth requirements, implied by protected debt, are common in short-term debt financing, whereas long-term debt instruments are usually unprotected or only partially protected.

${ }^{7}$ For simplicity, we assume that the firm cannot postpone its investment decision.
} 
The firm's EBIT at time $t$, defined as $\Pi_{t}$, is subject to a shock and, in particular, follows a geometric Brownian motion

$$
\frac{d \Pi_{t}}{\Pi_{t}}=\sigma d z \text { with } \Pi_{0}>0
$$

where $\sigma$ is the instantaneous standard deviation of $\frac{d \Pi_{t}}{\Pi_{t}} .8$

The assumptions on the firm's capital structure are the following:

1. the risk-free interest rate $r$ is fixed;

2. credit markets are perfectly competitive;

3. information is symmetric;

4. at time 0 , the firm borrows some resources and pays a constant coupon $C \leq \Pi_{0}$, which cannot be renegotiated.

The first three assumptions describe a perfectly efficient setting. Assumption 4 deserves some comment. It is worth noting that setting $C$ and then computing the market value of debt is equivalent to set first, the value of debt and then, compute the equilibrium interest rate. ${ }^{9}$ Assumption 4 also means that debt maturity is in line with the investment lifetime. ${ }^{10}$

Default occurs when the firm does not meet its debt obligation. In this case it is expropriated by the lender. Let us next introduce the two default conditions.

Definition 1 Under protected debt financing, default takes place when $\Pi_{t}$ falls to an exogenously given threshold point $\widetilde{\Pi}^{p}$.

As will be shown, full debt protection is ensured if the threshold point $\widetilde{\Pi}^{p}$ is equal to $C$.

\footnotetext{
${ }^{8}$ With no loss of generality, we assume that the drift of the Brownian motion is nil.

${ }^{9}$ Notice that the introduction of any trade-off is beyond the scope of this article. In the absence of any distress cost, therefore, $C$ is not the result of an optimal choice but rather is exogenously given.

${ }^{10}$ This assumption is realistic. As shown for instance by Graham and Harvey (2001) more than $63 \%$ of the US firms surveyed state that debt maturity is aimed at matching with assets' lifetime. On the other hand, BD assume a one-period debt financing strategy for a two-period investment project. However, they argue that the quality of results does not change if a new debt issue in the following period is assumed (see Bond and Devereux, 1999).
} 
Definition 2 Under unprotected debt financing, the threshold point $\widetilde{\Pi}^{u}$ is chosen optimally by shareholders at time 0.

In both cases, the existence of symmetric information means that, at time 0 , the creditor knows $\widetilde{\Pi}^{i}$ with $i=p, u$ before lending.

\section{The tax system}

Let us next introduce the S-based system, which allows the deduction of both effective interest payments and the opportunity cost of equity finance. Under full loss-offset ${ }^{11}$, the tax base will be

$$
\left\{\Pi_{t}-C-r\left[I-D^{i}\left(\widetilde{\Pi}^{i} ; \Pi_{0}, C\right)\right]\right\} \text { for } i=p, u \text { and } t \geq 0 .
$$

As can be seen the relief on equity finance is equal to the default-free interest rate times the book value of equity ${ }^{12},\left[I-D^{i}\left(\widetilde{\Pi}^{i} ; \Pi_{0}, C\right)\right]$, that is the difference between the historical cost of the investment project and the initial value of debt. ${ }^{13}$

Contrary to cash-flow systems, tax benefits are distributed along the investment's lifetime. This implies that, in the event of default, shareholders would fail to obtain a full tax benefit, unless an ad hoc rebate were granted. For this reason, BD propose a rebate equal to

$$
R^{i}\left(\widetilde{\Pi}^{i}\right)=\tau\left(I-\frac{\widetilde{\Pi}^{i}}{r}\right) \text { for } i=p, u,
$$

which is computed when default takes place. As shown in (2) the rebate is equal to the tax rate $\tau$ multiplied by the difference between the book value of the asset, i.e. $I$, and the net present value of the subsequent pre-tax cash flow in the event of default, i.e. $\frac{\widetilde{\Pi}^{i}}{r}$. This means that, under symmetric information, the government observes $\widetilde{\Pi}^{i}$ and then sets the rebate, thereby ensuring full compensation.

\footnotetext{
${ }^{11}$ For a discussion on the effects of no loss-offset, see e.g. Panteghini (2001, 2005).

${ }^{12}$ This rule, which only requires the knowledge of book values, is in line with the ACE tax proposal. See e.g. Devereux and Freeman (1991).

${ }^{13}$ According to assumption $4, D^{i}\left(\widetilde{\Pi}^{i} ; \Pi_{0}, C\right)$ represents both the market and book value of debt at time 0 .
} 


\subsection{The value of debt}

Like the firm, the lender is subject to S-based tax, though its tax rate may differ from the firm's one.

Before default, the lender' base is given by the difference between the interest payment (i.e. the coupon) and the opportunity cost of debt, i.e. $r D^{i}\left(\widetilde{\Pi}^{i} ; \Pi_{0}, C\right)$. In line with $\mathrm{BD}$, we assume that when default occurs, the tax relief is proportional to the net present value of the subsequent pre-tax cash flows of the project. In this case, the opportunity cost of debt will be $r$ times the market value of debt when $\Pi=\widetilde{\Pi}^{i}$, i.e. $D^{i}\left(\widetilde{\Pi}^{i} ; \widetilde{\Pi}^{i}, C\right)$. Given the tax rate $h$ the lender's after-tax cash flow will then be

$$
\left\{\begin{array}{cc}
C-h\left[C-r D^{i}\left(\widetilde{\Pi}^{i} ; \Pi_{0}, C\right)\right] & \text { before default } \\
\Pi_{t}-h\left[\Pi_{t}-r D^{i}\left(\widetilde{\Pi}^{i} ; \widetilde{\Pi}^{i}, C\right)\right] & \text { after default. }
\end{array}\right.
$$

Under market efficiency, the value of debt at time 0 is such that the following non-arbitrage condition (see Appendix A)

$$
r D^{i}\left(\widetilde{\Pi}^{i} ; \Pi_{0}, C\right)=C+\frac{\frac{\sigma^{2}}{2} \Pi^{2} D_{\Pi \Pi}^{i}\left(\widetilde{\Pi}^{i} ; \Pi_{0}, C\right)}{1-h}
$$

holds. Equation (3) entails the equality between a risk-free asset whose return is $r$ and a risky asset (the lender's credit) whose return is the effective interest rate, net of the default risk premium. As can be seen, taxation may be distortive since any change in the rate $h$ must be offset by a change in the value of debt in order for condition (3) to hold. Solving (3) we can write the value of debt at time 0 (see Appendix A) as a weighted average between the cash flow received before default and that received after:

$$
D^{i}\left(\widetilde{\Pi}^{i} ; \Pi_{0}, C\right)=\left[1-c\left(\widetilde{\Pi}^{i} ; \Pi_{0}\right)\right] \frac{C}{r}+c\left(\widetilde{\Pi}^{i} ; \Pi_{0}\right) \frac{\widetilde{\Pi}^{i}}{r} .
$$

The weight is $c\left(\widetilde{\Pi}^{i} ; \Pi_{0}\right) \equiv \frac{b\left(\widetilde{\Pi}^{i} ; \Pi_{0}\right)}{1-h+h b\left(\widetilde{\Pi}^{i} ; \Pi_{0}\right)}$, where $b\left(\widetilde{\Pi}^{i} ; \Pi_{0}\right) \equiv\left(\frac{\Pi_{0}}{\widetilde{\Pi}^{i}}\right)^{\beta_{2}}$, and $\beta_{2}<0$ is the negative root of the characteristic equation

$$
\phi(\beta) \equiv \frac{\sigma^{2}}{2} \beta(\beta-1)-r=0
$$


The term $c\left(\widetilde{\Pi}^{i} ; \Pi_{0}\right)$ measures the present value of 1 Euro contingent on the event default. As can be seen, it differs from the discount factor $b\left(\widetilde{\Pi}^{i} ; \Pi_{0}\right)$. This is due to the fact that an increase in the rate $h$ raises the aftertax risk premium and, consequently, $c\left(\widetilde{\Pi}^{i} ; \Pi_{0}\right)$. Therefore the inequality $b\left(\widetilde{\Pi}^{i} ; \Pi_{0}\right)<c\left(\widetilde{\Pi}^{i} ; \Pi_{0}\right)$ holds.

Let us next analyze the impact of the default conditions on the value of debt. By definition, full protection implies that the value of debt is equal to that of a default risk-free asset. Using (4) we can thus obtain

$$
\frac{C}{D^{p}\left(\widetilde{\Pi}^{p} ; \Pi_{0}, C\right)}=r
$$

Equality (6) implies that full protection holds if $\widetilde{\Pi}^{p}=C$. It is thus clear that taxation does not affect the value of debt. This is the case implicitly analyzed by BD.

When debt is unprotected, the trigger point $\widetilde{\Pi}^{u}$ is not necessarily equal to $C$. In this case, default entails that the lender's expected cash flow changes from $C$ to $\widetilde{\Pi}^{u}$. Using (4) we obtain the effective interest rate as the sum of the risk-free interest rate and the default risk premium:

$$
\frac{C}{D^{u}\left(\widetilde{\Pi}^{u} ; \Pi_{0}, C\right)}=r+\underbrace{c\left(\widetilde{\Pi}^{u} ; \Pi_{0}\right) \frac{C-\widetilde{\Pi}^{u}}{r}}_{\text {default risk premium }} .
$$

\subsection{The value of equity}

To compute the value of equity we must introduce a boundary condition regarding default. We know that at point $\Pi=\widetilde{\Pi}^{i}$ shareholders are expropriated, and, therefore, their claim is just equal to the tax rebate. Defining $E^{i}\left(\widetilde{\Pi}^{i} ; \Pi_{t}, C\right)$ as the value of equity therefore, we can write the following Value Matching Condition ${ }^{14}$

$$
E^{i}\left(\widetilde{\Pi}^{i} ; \widetilde{\Pi}^{i}, C\right)=R^{i}\left(\widetilde{\Pi}^{i}\right) \text { for } i=p, u
$$

\footnotetext{
${ }^{14}$ For details on this condition see Leland (1994) and Dixit and Pindyck (1994).
} 
Applying condition (8) (see Appendix B) we can compute the value of equity $E^{i}\left(\widetilde{\Pi}^{i} ; \Pi_{t}, C\right)=\frac{Y^{i}\left(\widetilde{\Pi}^{i} ; \Pi_{t}, C\right)}{r}+b\left(\widetilde{\Pi}^{i} ; \Pi_{t}\right)\left[R^{i}\left(\widetilde{\Pi}^{i}\right)-\frac{Y^{i}\left(\widetilde{\Pi}^{i} ; \widetilde{\Pi}^{i}, C\right)}{r}\right]$ for $t \geq 0$

where

$$
Y^{i}\left(\widetilde{\Pi}^{i} ; \Pi_{t}, C\right) \equiv(1-\tau)\left(\Pi_{t}-C\right)+\tau r\left[I-D^{i}\left(\widetilde{\Pi}^{i} ; \Pi_{0}, C\right)\right]
$$

is the net-of-tax cash flow. As shown in (9), the value of equity consists of two terms. The first term, $\frac{Y^{i}\left(\widetilde{\Pi}^{i} ; \Pi_{0}, C\right)}{r}$, is a perpetual rent proportional to aftertax cash flow. The second term measures the overall effect of default. This component is equal to the product between the discount factor $b\left(\widetilde{\Pi}^{i} ; \Pi_{t}\right)$ and the shareholders' net tax rebate $\left[R^{i}\left(\widetilde{\Pi}^{i}\right)-\frac{Y^{i}\left(\widetilde{\Pi}^{i} ; \widetilde{\Pi}^{i}, C\right)}{r}\right]$, i.e. the tax rebate received in the event of default minus future cash flow lost by expropriation. As can be seen, the shareholders' discount factor is $b\left(\widetilde{\Pi}^{i} ; \Pi_{t}\right)$, and thus differs from the lender's one. ${ }^{15}$

\section{Neutrality results}

Let us next analyze the neutrality properties of the S-based tax system. Here we deal with both real and financial neutrality, when the firm's decisions are made at time $t=0$. To define real neutrality let us write the firm's Net Present Value

$$
N P V^{i}\left(\widetilde{\Pi}^{i} ; \Pi_{0}, C\right)=E^{i}\left(\widetilde{\Pi}^{i} ; \Pi_{0}, C\right)+D^{i}\left(\widetilde{\Pi}^{i} ; \Pi_{0}, C\right)-I .
$$

Following Brown (1948) we can thus state that

Condition 1 Real neutrality holds if

$$
N P V^{i}\left(\widetilde{\Pi}^{i} ; \Pi_{0}, C\right)=(1-\tau) N P V^{*}\left(\Pi_{0}\right),
$$

where $N P V^{*}\left(\Pi_{0}\right) \equiv \frac{\Pi_{0}}{r}-I$ is the Net Present Value in the absence of taxation.

\footnotetext{
${ }^{15}$ Remember that $c\left(\widetilde{\Pi}^{i} ; \Pi_{t}\right)>b\left(\widetilde{\Pi}^{i} ; \Pi_{t}\right)$.
} 
As pointed out by Johansson (1969, p.104), equation (11) entails that an 'identical ranking of alternative investments is obtained in a pre-tax and post-tax profitability analysis'. Moreover, condition (11) implies that the Modigliani-Miller Theorem holds.

Substituting (4) and (9) into (10) yields

$$
N P V^{i}\left(\widetilde{\Pi}^{i} ; \Pi_{0}, C\right)=(1-\tau) N P V^{*}\left(\Pi_{0}\right)+X\left(\widetilde{\Pi}^{i} ; \Pi_{0}, C\right)
$$

where

$$
\begin{gathered}
X\left(\widetilde{\Pi}^{i} ; \Pi_{0}, C\right) \equiv\left\{(1-\tau)\left[1-b\left(\widetilde{\Pi}^{i} ; \Pi_{0}, C\right)\right]\left[D^{i}\left(\widetilde{\Pi}^{i} ; \Pi_{0}, C\right)-\frac{C}{r}\right]\right\}+ \\
+\left\{b\left(\widetilde{\Pi}^{i} ; \Pi_{0}, C\right)\left[D^{i}\left(\widetilde{\Pi}^{i} ; \Pi_{0}, C\right)-D^{i}\left(\widetilde{\Pi}^{i} ; \widetilde{\Pi}^{i}, C\right)\right]\right\}
\end{gathered}
$$

measures the overall tax distortion. This distortion consists of two terms. The first one measures the present value of the after-tax risk premium before default. The second term is given by the expected devaluation of debt conditional on the event of debt. If therefore $X\left(\widetilde{\Pi}^{i} ; \Pi_{0}, C\right)=0$, real neutrality is ensured.

The second neutrality condition regards unprotected debt. In this case, indeed, shareholders can decide when to default. Defining $\widetilde{\Pi}_{L F}^{u}$ as the default trigger point in the absence of taxation, we can thus state that

Condition 2 Financial neutrality holds if default timing is not affected by taxation, i.e. $\widetilde{\Pi}^{u}=\widetilde{\Pi}_{L F}^{u}$.

\subsection{Protected debt}

Let us start with protected debt financing. We can write the following

Proposition 1 If debt is fully protected the S-based system is neutral.

Proof. See Appendix C.

As pointed out in Section 3.1 full protection is ensured if $\widetilde{\Pi}^{p}=C$. This implies that $D^{p}\left(\widetilde{\Pi}^{p} ; \Pi_{0}, C\right)=D^{p}\left(C ; \Pi_{0}, C\right)$. Moreover, the lender's postdefault claim is equal to $D^{i}\left(\widetilde{\Pi}^{i} ; \widetilde{\Pi}^{i}, C\right)=\frac{\widetilde{\Pi}^{i}}{r}, i=u, p$ (see Appendix C). Therefore the shareholders' rebate is equal to $R^{p}(C)=\tau\left(I-\frac{C}{r}\right)$ : this makes $X\left(\widetilde{\Pi}^{p} ; \Pi_{0}, C\right)$ fall to zero. The intuition behind this result is straightforward: 
the cash flow tax and equivalently, any imputed income tax systems can be thought of as ensuring relief for both the risk-free rate and the risk premium (see Devereux, 2003). As shown in (6), however, the default risk premium falls to zero and any distortive effect of $h$ on the value of debt vanishes.

\subsection{Unprotected debt}

Proposition 1 is in line with BD's findings. When debt is unprotected, however, results are quite different. In this case, the default trigger point $\widetilde{\Pi}^{u}$ is optimally chosen by maximizing the value of equity, i.e.

$$
\max _{\widetilde{\Pi}^{u}} E^{u}\left(\widetilde{\Pi}^{u} ; \Pi_{0}, C\right) \text {. }
$$

Solving (13) we obtain

Proposition 2 Under unprotected debt financing the inequalities $\widetilde{\Pi}^{u}<\widetilde{\Pi}_{L F}^{u}<$ $C$ hold $\forall \tau$.

Proof. See Appendix D.

Proposition 2 shows that shareholders postpone their default decision. To get the intuition behind the result it is worth noting that $\widetilde{\Pi}_{L F}^{u}<C$, namely that, without taxation, the default option is exercised when the net cash flow is negative. This is due to the fact that default is an irreversible choice $^{16}$ : shareholders are aware that the exercise of the put option entails the irreversible loss of any opportunity to exploit future profit recoveries. Under the S-based system, the lower the point $\widetilde{\Pi}^{u}$ is, the greater is the value of the rebate received by shareholders. Not surprisingly therefore we have $\widetilde{\Pi}^{u}<\widetilde{\Pi}_{L F}^{u}$, i.e. default timing is delayed. ${ }^{17}$

Let us next focus on real effects. We can prove the following:

Proposition 3 Under unprotected debt financing a real distortion arises if $h \neq \tau$, i.e.

$$
N P V^{u}\left(\widetilde{\Pi}^{u} ; \Pi_{0}, C\right)-(1-\tau) N P V^{*}\left(\Pi_{0}\right) \propto(\tau-h)
$$

\footnotetext{
${ }^{16}$ Remember that the default trigger point $\widetilde{\Pi}^{u}$ is set at time 0 and is known by the lender.

${ }^{17}$ Notice that this behaviour is stimulated by full loss-offset provisions. In this case, loss-making firms enjoy a tax benefit and may be induced to further postpone default.
} 
Proof. See Appendix E.

The intuition behind Proposition 3 is as follows. Assume that initially the equality $\tau=h$ holds. Then suppose that $h$ is cut. This tax rate change has a twofold effect. On the one hand, it reduces the value of debt $D^{u}\left(\widetilde{\Pi}^{u} ; \Pi_{0}, C\right)$, and, on the other hand, raises the shareholders tax benefit $\operatorname{\tau r}\left[I-D^{u}\left(\widetilde{\Pi}^{u} ; \Pi_{0}, C\right)\right]$, thereby increasing the value of equity. Proposition 3 thus shows that the decrease in $D^{u}\left(\widetilde{\Pi}^{u} ; \Pi_{0}, C\right)$ is overcompensated by the increase in $E^{u}\left(\widetilde{\Pi}^{u} ; \Pi_{0}, C\right)$, so inequality $N P V^{u}\left(\widetilde{\Pi}^{u} ; \Pi_{0}, C\right)>$ $(1-\tau) N P V^{*}\left(\Pi_{0}\right)$ holds and we have overinvestment. ${ }^{18}$ The converse is true if $h$ is raised.

The above result is not surprising if we disregard the firm's ownership and rather, focus on the project value. We can in fact state that inequality $\tau>h$ is equivalent to an expected tax rate cut occurring whenever $\Pi$ falls to $\widetilde{\Pi}^{u}$. This expected tax cut thus stimulates investment. ${ }^{19}$ The converse is true if $\tau<h$.

\section{Concluding remarks and policy implications}

In this article we have shown that the neutrality properties of an S-based system depend on the default condition assumed. In particular, we have shown that both real and financial neutrality hold when debt is protected.

When debt is unprotected, results are different. Real neutrality is ensured only under uniform taxation. Moreover, financial neutrality never holds, as shareholders are induced to delay their default decision.

In a companion article (Panteghini, 2004) we showed that an R-based system, allowing for deduction of debt at the risk-free rate, ensures both real and financial neutrality irrespective of whether debt is protected or unprotected. This allows us to conclude that in terms of neutrality, a R-based system is preferable to a S-based one even in perfectly efficient capital markets.

\footnotetext{
${ }^{18}$ Notice that under full debt protection, the default premium is nil and, therefore, this distortive effect disappears.

${ }^{19} \mathrm{~A}$ similar point is made by Bond and Devereux (1995) where they show that any expected future tax rate change is distortive.
} 


\section{A The computation of (3) and (4)}

Using dynamic programming, the value of debt can be written as follows

$D^{i}\left(\widetilde{\Pi}^{i} ; \Pi_{t}, C\right)= \begin{cases}\left\{C-h\left[C-r D^{i}\left(\Pi_{0}, C\right)\right]\right\} d t+e^{-r d t} \xi\left[D^{i}\left(\Pi_{t}+d \Pi_{t}, C\right)\right] & \text { before default }, \\ {\left[\Pi_{t}-h\left(\Pi-r D^{i}\left(\widetilde{\Pi}^{i}, C\right)\right)\right] d t+e^{-r d t} \xi\left[D^{i}\left(\Pi_{t}+d \Pi_{t}, C\right)\right]} & \text { otherwise. }\end{cases}$

where $\xi[$.$] is the expectation operator.$

Let us first focus on the pre-default value of debt. Expanding the RHS of (15) and applying Itô's Lemma, one obtains

$$
\begin{aligned}
& D^{i}\left(\widetilde{\Pi}^{i} ; \Pi_{t}, C\right)=\left[(1-h) C+h r D^{i}\left(\widetilde{\Pi}^{i} ; \Pi_{0}, C\right)\right] d t+ \\
& +(1-r d t)\left[D^{i}\left(\widetilde{\Pi}^{i} ; \Pi_{t}, C\right)+\frac{\sigma^{2}}{2} D_{\Pi \Pi}^{i}\left(\widetilde{\Pi}^{i} ; \Pi_{t}, C\right)\right] .
\end{aligned}
$$

Recalling that $(d t)^{2} \rightarrow 0$ one easily obtains the following non-arbitrage condition

$r D^{i}\left(\widetilde{\Pi}^{i} ; \Pi_{t}, C\right)=\left[(1-h) C+h r D^{i}\left(\widetilde{\Pi}^{i} ; \Pi_{0}, C\right)\right]+\frac{\sigma^{2}}{2} \Pi^{2} D_{\Pi \Pi}^{i}\left(\widetilde{\Pi}^{i} ; \Pi_{t}, C\right)$

Manipulating (17) one easily obtains (3).

Let us next solve (17). Thus before default we obtain

$$
D^{i}\left(\widetilde{\Pi}^{i} ; \Pi_{t}, C\right)=\frac{(1-h) C+h r D^{i}\left(\widetilde{\Pi}^{i} ; \Pi_{0}, C\right)}{r}+\sum_{j=1}^{2} G_{j}^{i} \Pi_{t}^{\beta_{j}}
$$

where $\beta_{1}$ and $\beta_{2}$ are the positive and negative root of the characteristic equation (5), respectively. After default the value of debt is

$$
D^{i}\left(\widetilde{\Pi}^{i} ; \Pi_{t}, C\right)=\frac{(1-h) \Pi_{t}+h r D^{i}\left(\widetilde{\Pi}^{i} ; \widetilde{\Pi}^{i}, C\right)}{r}+\sum_{j=1}^{2} L_{j}^{i} \Pi_{t}^{\beta_{j}}
$$

We can now compute the values of $G_{j}^{i}$ and $L_{j}^{i}$ for $j=1,2$. To do so we must introduce two boundary conditions, which are in line with the assumption 
of perfectly efficient capital markets. ${ }^{20}$ Firstly, we assume that no financial bubbles exist. This means that $G_{1}^{i}=L_{1}^{i}=0$. Secondly, we assume that when $\Pi_{t}=0$, the lender's claim is worth the tax benefit, namely

$$
D^{i}\left(\widetilde{\Pi}^{i} ; 0, C\right)=h D^{i}\left(\widetilde{\Pi}^{i} ; \widetilde{\Pi}^{i}, C\right)
$$

This implies that $L_{2}^{i}=0$. Using (19) we thus have

$$
D^{i}\left(\widetilde{\Pi}^{i} ; \widetilde{\Pi}^{i}, C\right)=\frac{\widetilde{\Pi}^{i}}{r} .
$$

To compute $G_{2}^{i}$, let the two branches (18) and (19) meet at point $\Pi_{t}=\widetilde{\Pi}^{i}$. Using (20) we thus have

$$
D^{i}\left(\widetilde{\Pi}^{i} ; \widetilde{\Pi}^{i}, C\right)=\frac{(1-h) C+h r D^{i}\left(\widetilde{\Pi}^{i} ; \Pi_{0}, C\right)}{r}+G_{2}^{i} \widetilde{\Pi}^{i^{\beta_{2}}}=\frac{\widetilde{\Pi}^{i}}{r} .
$$

Using (18) and setting $\Pi=\Pi_{0}$ yields the value of debt at time 0

$$
D^{i}\left(\widetilde{\Pi}^{i} ; \Pi_{0}, C\right)=\frac{C}{r}+\frac{G_{2}^{i} \Pi_{0}^{\beta_{2}}}{1-h} .
$$

Substituting (22) into (21), and solving for $G_{2}^{i}$ we have

$$
G_{2}^{i}=\frac{\widetilde{\Pi}^{i}-C}{r}\left[\frac{h}{1-h} \Pi_{0}^{\beta_{2}}+\widetilde{\Pi}^{i^{\beta_{2}}}\right]^{-1}
$$

Rearranging yields (4).

\section{B The computation of (9)}

The firm's value of equity can be written as

$E^{i}\left(\widetilde{\Pi}^{i} ; \Pi_{t}, C\right)= \begin{cases}Y^{i}\left(\widetilde{\Pi}^{i} ; \Pi_{t}, C\right) d t+e^{-r d t} \xi\left[E\left(\widetilde{\Pi}^{i} ; \Pi_{t}+d \Pi_{t}, C\right)\right] & \text { before default } \\ R^{i}\left(\widetilde{\Pi}^{i}\right) & \text { otherwise. }\end{cases}$

\footnotetext{
${ }^{20}$ For further details on this boundary conditions see e.g. Dixit and Pindyck (1994).
} 
As shown in (24), in the event of default, shareholders are expropriated and the value of their claim is simply equal to $R^{i}\left(\widetilde{\Pi}^{i}\right)$.

Let us next focus on the pre-default case. Expanding the RHS of (24), one obtains the following Bellman equation

$$
r E^{i}\left(\widetilde{\Pi}^{i} ; \Pi_{t}, C\right)=Y^{i}\left(\widetilde{\Pi}^{i} ; \Pi_{t}, C\right)+\frac{\sigma^{2}}{2} \Pi^{2} E_{\Pi \Pi}^{i}\left(\widetilde{\Pi}^{i} ; \Pi_{t}, C\right) .
$$

where

$$
Y^{i}\left(\widetilde{\Pi}^{i} ; \Pi_{t}, C\right) \equiv(1-\tau)\left(\Pi_{t}-C\right)+\tau r\left[I-D^{i}\left(\widetilde{\Pi}^{i} ; \Pi_{0}, C\right)\right] .
$$

Solving (25) yields

$$
E^{i}\left(\widetilde{\Pi}^{i} ; \Pi_{t}, C\right)=\frac{Y^{i}\left(\widetilde{\Pi}^{i} ; \Pi_{t}, C\right)}{r}+\sum_{j=1}^{2} F_{j}^{i} \Pi_{t}^{\beta_{2}}
$$

Let us next compute $F_{j}^{i}$ for $j=1,2$. Notice that, in the absence of any bubble, we have $F_{1}^{i}=0$. To compute $F_{2}^{i}$ we use (26) and apply the Value Matching Condition (8). We thus obtain

$$
\frac{Y^{i}\left(\widetilde{\Pi}^{i} ; \widetilde{\Pi}^{i}, C\right)}{r}+F_{2}^{i} \widetilde{\Pi}^{i \beta_{2}}=R^{i}\left(\widetilde{\Pi}^{i}\right)=\tau\left(I-\frac{\widetilde{\Pi}^{i}}{r}\right),
$$

which yields

$$
F_{2}^{i}=\left[R^{i}\left(\widetilde{\Pi}^{i}\right)-\frac{Y^{i}\left(\widetilde{\Pi}^{i} ; \widetilde{\Pi}^{i}, C\right)}{r}\right]\left(\widetilde{\Pi}^{i}\right)^{-\beta_{2}} .
$$

Substituting (27) into (26), at point $\Pi_{0}$ yields (9).

\section{Proof of Proposition 1}

Substituting (6) into (4), we easily obtain the equality $\widetilde{\Pi}^{p}=C$. This means that

$$
D^{p}\left(\widetilde{\Pi}^{p} ; \Pi_{0}, C\right)=D^{p}\left(C ; \Pi_{0}, C\right)=\frac{C}{r} .
$$

Moreover using (20) we obtains the following inequalities

$$
D^{p}\left(\widetilde{\Pi}^{p} ; \widetilde{\Pi}^{p}, C\right)=D^{p}(C ; C, C)=\frac{C}{r} .
$$

Substituting (28) and (29) into (10) yields (11). This proves Proposition 1. 


\section{Proof of Proposition 2}

Recall (9) and (27), and rewrite the value of equity as

$$
E^{u}\left(\widetilde{\Pi}^{u} ; \Pi_{0}, C\right)=\left[\frac{(1-\tau) \Pi_{0}-C}{r}+\tau I\right]+H\left(\widetilde{\Pi}^{u} ; \Pi_{0}, C\right)
$$

with

$$
H\left(\widetilde{\Pi}^{u} ; \Pi_{0}, C\right) \equiv-\tau \frac{G_{2}^{u} \Pi_{0}^{\beta_{2}}}{1-h}\left[1-\left(\frac{\Pi_{0}}{\widetilde{\Pi}^{u}}\right)^{\beta_{2}}\right]-\frac{\left(\widetilde{\Pi}^{u}-C\right)}{r}\left(\frac{\Pi_{0}}{\widetilde{\Pi}^{u}}\right)^{\beta_{2}}
$$

and

$$
\frac{G_{2}^{u} \Pi_{0}^{\beta_{2}}}{1-h}=\frac{\widetilde{\Pi}^{u}-C}{r} \frac{\left(\frac{\Pi_{0}}{\widetilde{\Pi}^{u}}\right)^{\beta_{2}}}{\left[(1-h)+h\left(\frac{\Pi_{0}}{\widetilde{\Pi}^{u}}\right)^{\beta_{2}}\right]}
$$

Compute now the first order condition of problem (13). It is clear that

$$
\frac{\partial E^{u}\left(\widetilde{\Pi}^{u} ; \Pi_{0}, C\right)}{\partial \widetilde{\Pi}^{u}}=\frac{\partial H\left(\widetilde{\Pi}^{u} ; \Pi_{0}, C\right)}{\partial \widetilde{\Pi}^{u}}=0 .
$$

where

$$
\begin{gathered}
\frac{\partial H\left(\widetilde{\Pi}^{u} ; \Pi_{0}, C\right)}{\partial \widetilde{\Pi}^{u}}=\frac{\partial}{\partial \widetilde{\Pi}^{u}}\left[-\frac{\left(\widetilde{\Pi}^{u}-C\right)}{r}\left(\frac{\Pi}{\widetilde{\Pi}^{u}}\right)^{\beta_{2}}\right]\left\{\frac{1+(\tau-h)\left[1-\left(\frac{\Pi_{0}}{\widetilde{\Pi}^{u}}\right)^{\beta_{2}}\right]}{\left[(1-h)+h\left(\frac{\Pi_{0}}{\widetilde{\Pi}^{u}}\right)^{\beta_{2}}\right]}\right\}+ \\
-\left[\frac{\left(\widetilde{\Pi}^{u}-C\right)}{r}\left(\frac{\Pi_{0}}{\widetilde{\Pi}^{u}}\right)^{\beta_{2}}\right] \cdot \frac{\partial}{\partial \widetilde{\Pi}^{u}}\left\{\frac{1+(\tau-h)\left[1-\left(\frac{\Pi_{0}}{\widetilde{\Pi}^{u}}\right)^{\beta_{2}}\right]}{\left[(1-h)+h\left(\frac{\Pi_{0}}{\widetilde{\Pi}^{u}}\right)^{\beta_{2}}\right]}\right\}
\end{gathered}
$$

with

$$
\frac{\partial}{\partial \widetilde{\Pi}^{u}}\left[-\frac{\left(\widetilde{\Pi}^{u}-C\right)}{r}\left(\frac{\Pi_{0}}{\widetilde{\Pi}^{u}}\right)^{\beta_{2}}\right]=-\frac{\left(1-\beta_{2}\right)}{r}\left(\frac{\Pi_{0}}{\widetilde{\Pi}^{u}}\right)^{\beta_{2}}\left(\widetilde{\Pi}^{u}\right)^{-1}\left(\widetilde{\Pi}^{u}-\frac{\beta_{2}}{\beta_{2}-1} C\right),
$$

and

$$
\frac{\partial}{\partial \widetilde{\Pi}^{u}}\left\{1+\tau \frac{\left[1-\left(\frac{\Pi_{0}}{\widetilde{\Pi}^{u}}\right)^{\beta_{2}}\right]}{\left[(1-h)+h\left(\frac{\Pi_{0}}{\widetilde{\Pi}^{u}}\right)^{\beta_{2}}\right]}\right\}=\left(\frac{\tau}{h}\right) \frac{\beta_{2}\left(\frac{\Pi_{0}}{\widetilde{\Pi}^{u}}\right)^{\beta_{2}}\left(\widetilde{\Pi}^{u}\right)^{-1}}{\left\{1-h\left[1-\left(\frac{\Pi_{0}}{\widetilde{\Pi}^{u}}\right)^{\beta_{2}}\right]\right\}^{2}}<0 .
$$


We thus have

$$
\begin{gathered}
\frac{\partial H\left(\widetilde{\Pi}^{u} ; \Pi_{0}, C\right)}{\partial \widetilde{\Pi}^{u}=-} \frac{\left(1-\beta_{2}\right)}{r}\left(\frac{\Pi_{0}}{\widetilde{\Pi}^{u}}\right)^{\beta_{2}}\left(\widetilde{\Pi}^{u}\right)^{-1}\left\{\widetilde{\Pi}^{u}-\frac{\beta_{2}}{\beta_{2}-1} C\right\}\left\{1+\tau \frac{\left[1-\left(\frac{\Pi_{0}}{\widetilde{\Pi}^{u}}\right)^{\beta_{2}}\right]}{\left[(1-h)+h\left(\frac{\Pi_{0}}{\Pi^{u}}\right)^{\beta_{2}}\right]}\right\}- \\
-\left[\frac{\left(\widetilde{\Pi}^{u}-C\right)}{r}\left(\frac{\Pi_{0}}{\widetilde{\Pi}^{u}}\right)^{\beta_{2}}\right]\left(\frac{\tau}{h}\right) \frac{\beta_{2}\left(\frac{\Pi_{0}}{\widetilde{\Pi}^{u}}\right)^{\beta_{2}}\left(\widetilde{\Pi}^{u}\right)^{-1}}{\left\{1-h\left[1-\left(\frac{\Pi_{0}}{\widetilde{\Pi}^{u}}\right)^{\beta_{2}}\right]\right\}^{2}}=0
\end{gathered}
$$

Using (30) we obtain the following equation

$$
\widetilde{\Pi}^{u}=\frac{\beta_{2}}{\beta_{2}-1} C+\left(\frac{\tau}{h}\right) \frac{\frac{\beta_{2}}{\beta_{2}-1}\left(\widetilde{\Pi}^{u}-C\right)\left(\frac{\Pi_{0}}{\widetilde{\Pi}^{u}}\right)^{\beta_{2}}}{\left\{1-h\left[1-\left(\frac{\Pi_{0}}{\widetilde{\Pi}^{u}}\right)^{\beta_{2}}\right]\right\}\left\{1+(\tau-h)\left[1-\left(\frac{\Pi_{0}}{\widetilde{\Pi}^{u}}\right)^{\beta_{2}}\right]\right\}}
$$

To analyze the distortive effect of taxation, recall (30), and set $\tau=h=0$. We thus obtain the laissez-faire threshold point:

$$
\widetilde{\Pi}_{L F}^{u}=\frac{\beta_{2}}{\beta_{2}-1} C
$$

By contradiction we can now prove that $\widetilde{\Pi}^{u}<\widetilde{\Pi}_{L F}^{u}$. Assume $a b$ absurdo that $\widetilde{\Pi}^{u}>C$. In this case equation (31) holds, but it is straightforward to see that $H\left(\widetilde{\Pi}^{u} ; \Pi_{0}, C\right)<0$. This entails that no solution $\widetilde{\Pi}^{u}>C$ ensures a maximum. Moreover, assume ab absurdo that $\frac{\beta_{2}}{\beta_{2}-1} C<\widetilde{\Pi}^{u}<C$. In this case (31) does not hold: thus no solution can be found. Therefore, the solution must be such that inequality $\widetilde{\Pi}^{u}<\frac{\beta_{2}}{\beta_{2}-1} C$ holds. In this case, indeed, equation (31) holds, and $H\left(\widetilde{\Pi}^{u} ; \Pi_{0}, C\right)>0$. This proves Proposition 2.

\section{E Proof of Proposition 3}

Using (4) we can rewrite (12) as

$$
N P V^{u}\left(\widetilde{\Pi}^{u} ; \Pi_{0}, C\right)=(1-\tau) N P V^{*}\left(\Pi_{0}\right)+X\left(\widetilde{\Pi}^{u} ; \Pi_{0}, C\right)
$$


where

$$
\begin{aligned}
X\left(\widetilde{\Pi}^{u} ; \Pi_{0}, C\right) & \equiv\left\{(1-\tau)\left[1-b\left(\widetilde{\Pi}^{u} ; \Pi_{0}, C\right)\right]\left[D^{u}\left(\widetilde{\Pi}^{u} ; \Pi_{0}, C\right)-\frac{C}{r}\right]\right\}+ \\
& +\left\{b\left(\widetilde{\Pi}^{u} ; \Pi_{0}, C\right)\left[D^{u}\left(\widetilde{\Pi}^{u} ; \Pi_{0}, C\right)-\frac{\widetilde{\Pi}^{u}}{r}\right]\right\}
\end{aligned}
$$

Let us substitute (4) into (33) and rearrange, so as to obtain

$$
N P V^{u}\left(\widetilde{\Pi}^{u} ; \Pi_{0}, C\right)=(1-\tau) N P V^{*}\left(\Pi_{0}\right)-\frac{\left(\widetilde{\Pi}^{u}-C\right)}{r} b\left(\widetilde{\Pi}^{u} ; \Pi_{0}\right) \cdot \frac{(\tau-h)\left[1-b\left(\widetilde{\Pi}^{u} ; \Pi_{0}\right)\right]}{1-h\left[1-b\left(\widetilde{\Pi}^{u} ; \Pi_{0}\right)\right]} .
$$

Since $\widetilde{\Pi}^{u}<C$, we can write (14), thereby proving Proposition 3 . 


\section{References}

[1] Becker J. and C. Fuest (2005), Does Germany Collect Revenue from Taxing Capital Income?, CESifo Area Conference on Public Sector Economics.

[2] Boadway R. and N. Bruce (1984), A General Proposition on the Design of a Neutral Business Tax, Journal of Public Economics, July 1984, v. 24, iss. 2, pp. 231-39.

[3] Bond S.R. (2000), Levelling Up or Levelling Down? Some Reflections in the ACE and CBIT Proposals, and the Future of the Corporate Tax Base, in S. Cnossen (ed.), Taxing Capital Income in the European Union - Issues and Options for Reform, Oxford University Press, Oxford.

[4] Bond S.R. and Devereux M.P. (1995), On the Design of a Neutral Business Tax under Uncertainty, Journal of Public Economics, 58, pp. 57-71.

[5] Bond S.R. and Devereux M.P. (1999), Generalised R-based and S-based Taxes under Uncertainty, IFS Working Paper Series no. W99/9.

[6] Bond S.R. and Devereux M.P. (2003), Generalised R-based and S-based Taxes under Uncertainty, Journal of Public Economics, 87, pp. 12911311.

[7] Bordignon M., S. Giannini, and P.M. Panteghini (2001), Reforming Business Taxation: Lessons from Italy?, International Tax and Public Finance, v. 8, iss. 2, pp. 191-210.

[8] Brennan M. and E. Schwartz (1978), Corporate Income Taxes, Valuation, and the Problem of Optimal Capital Structure, Journal of Business, 51, pp.103-14.

[9] Brown E.C. (1948), Business-Income Taxation and Investment Incentives, in L.A. Meltzer, E.D. Domar et al., eds., Income, Employment and Public Policy, Essays in Honor of A.H. Hansen, W.W. Norton \& c., New York.

[10] Cnossen S. (2005), The Future of Capital Income Taxation in the European Union, CESifo Area Conference on Public Sector Economics. 
[11] Devereux M.P. (2003), Taxing Risky Investment, CEPR Discussion Paper No.4053.

[12] Devereux M.P. and H. Freeman (1991), A General Neutral Profits Tax, Fiscal Studies, August, 12, pp. 1-15.

[13] Dixit A. and R.S. Pindyck (1994), Investment under Uncertainty, Princeton University Press.

[14] Fehr H. and W. Wiegard (2001), The Incidence of an Extended ACE Corporation Tax, CESifo Working Paper Series No. 484.

[15] Graham J.R. and C.R. Harvey (2001), The Theory and Practice of Corporate Finance: Evidence from the Field, Journal of Financial Economics, v. 60, iss. 2-3, pp. 187-243.

[16] IFS (1991), ed., Equity for Companies: a Corporation Tax for the 1990s, A Report of the IFS Capital Taxes Group chaired by M. Gammie, The Institute for Fiscal Studies, Commentary 26, London.

[17] Johansson S.-E. (1969), Income Taxes and Investment Decisions, Swedish Journal of Economics, 71, pp. 104-110.

[18] Keen M. (2003), Tax Reform in Italy, Tax Notes International, February, pp. 665-682.

[19] Keen M. and J. King (2002), The Croatian Profit Tax: An ACE in Practice, Fiscal Studies, v. 23, iss. 3, pp. 401-18.

[20] Leland H.E. (1994), Corporate Debt Value, Bond Covenants, and Optimal Capital Structure, Journal of Finance, September, 49, iss. 4, pp. 1213-52.

[21] Panteghini P.M. (2001), Corporate Tax Asymmetries under Investment Irreversibility, FinanzArchiv, Vol. 58, 2001, pp. 207-226.

[22] Panteghini P.M. (2004), Neutrality Properties of Firm Taxation under Default Risk, Economics Bulletin, Vol. 8, N.4, pp.1-7.

[23] Panteghini P.M. (2004), Wide versus Narrow Tax Bases under Optimal Investment Timing, FinanzArchiv, Vol. 60, N. 4, pp. 482-493. 
[24] Panteghini P.M. (2005), Asymmetric Taxation under Incremental and Sequential Investment, Journal of Public Economic Theory, forthcoming.

[25] Smith C.W., Jr., and J.B. Warner (1977), Bankruptcy, Secured Debt, and Optimal Capital Structure: Comment, Journal of Finance, 34, pp. $247-51$.

[26] Sørensen P.B. (2003), Neutral Taxation of Shareholder Income: A Norwegian Tax Reform Proposal, CESifo Working Paper No. 1036.

[27] Zodrow G. (2003), Alternative Forms of Direct Consumption Taxes: The Croatian Approach, Tax Notes International, October 20, pp. 239-51. 


\section{CESifo Working Paper Series}

(for full list see www.cesifo-group.de)

1429 Sören Blomquist and Luca Micheletto, Optimal Redistributive Taxation when Government's and Agents' Preferences Differ, March 2005

1430 Olof Åslund and Peter Fredriksson, Ethnic Enclaves and Welfare Cultures - QuasiExperimental Evidence, March 2005

1431 Paul De Grauwe, Roberto Dieci and Marianna Grimaldi, Fundamental and NonFundamental Equilibria in the Foreign Exchange Market. A Behavioural Finance Framework, March 2005

1432 Peter Egger, Stefan Gruber, Mario Larch and Michael Pfaffermayr, Knowledge-Capital Meets New Economic Geography, March 2005

1433 George Economides and Apostolis Philippopoulos, Should Green Governments Give Priority to Environmental Policies over Growth-Enhancing Policies?, March 2005

1434 George W. Evans and Seppo Honkapohja, An Interview with Thomas J. Sargent, March 2005

1435 Helge Berger and Volker Nitsch, Zooming Out: The Trade Effect of the Euro in Historical Perspective, March 2005

1436 Marc-Andreas Muendler, Rational Information Choice in Financial Market Equilibrium, March 2005

1437 Martin Kolmar and Volker Meier, Intra-Generational Externalities and InterGenerational Transfers, March 2005

1438 M. Hashem Pesaran and Takashi Yamagata, Testing Slope Homogeneity in Large Panels, March 2005

1439 Gjermund Nese and Odd Rune Straume, Industry Concentration and Strategic Trade Policy in Successive Oligopoly, April 2005

1440 Tomer Blumkin and Efraim Sadka, A Case for Taxing Education, April 2005

1441 John Whalley, Globalization and Values, April 2005

1442 Denise L. Mauzerall, Babar Sultan, Namsoug Kim and David F. Bradford, Charging $\mathrm{NO}_{x}$ Emitters for Health Damages: An Exploratory Analysis, April 2005

1443 Britta Hamburg, Mathias Hoffmann and Joachim Keller, Consumption, Wealth and Business Cycles in Germany, April 2005 
1444 Kohei Daido and Hideshi Itoh, The Pygmalion Effect: An Agency Model with Reference Dependent Preferences, April 2005

1445 John Whalley, Rationality, Irrationality and Economic Cognition, April 2005

1446 Henning Bohn, The Sustainability of Fiscal Policy in the United States, April 2005

1447 Torben M. Andersen, Is there a Role for an Active Fiscal Stabilization Policy? April 2005

1448 Hans Gersbach and Hans Haller, Bargaining Power and Equilibrium Consumption, April 2005

1449 Jerome L. Stein, The Transition Economies: A NATREX Evaluation of Research, April 2005

1450 Raymond Riezman, John Whalley and Shunming Zhang, Metrics Capturing the Degree to which Individual Economies are Globalized, April 2005

1451 Romain Ranciere, Aaron Tornell and Frank Westermann, Systemic Crises and Growth, April 2005

1452 Plutarchos Sakellaris and Focco W. Vijselaar, Capital Quality Improvement and the Sources of Growth in the Euro Area, April 2005

1453 Kevin Milligan and Michael Smart, Regional Grants as Pork Barrel Politics, April 2005

1454 Panu Poutvaara and Andreas Wagener, To Draft or not to Draft? Efficiency, Generational Incidence, and Political Economy of Military Conscription, April 2005

1455 Maurice Kugler and Hillel Rapoport, Skilled Emigration, Business Networks and Foreign Direct Investment, April 2005

1456 Yin-Wong Cheung and Eiji Fujii, Cross-Country Relative Price Volatility: Effects of Market Structure, April 2005

1457 Margarita Katsimi and Thomas Moutos, Inequality and Relative Reliance on Tariffs: Theory and Evidence, April 2005

1458 Monika Bütler, Olivia Huguenin and Federica Teppa, Why Forcing People to Save for Retirement may Backfire, April 2005

1459 Jos Jansen, The Effects of Disclosure Regulation of an Innovative Firm, April 2005

1460 Helge Bennmarker, Kenneth Carling and Bertil Holmlund, Do Benefit Hikes Damage Job Finding? Evidence from Swedish Unemployment Insurance Reforms, May 2005

1461 Steffen Huck, Kai A. Konrad and Wieland Müller, Merger without Cost Advantages, May 2005 
1462 Louis Eeckhoudt and Harris Schlesinger, Putting Risk in its Proper Place, May 2005

1463 Hui Huang, John Whalley and Shunming Zhang, Trade Liberalization in a Joint Spatial Inter-Temporal Trade Model, May 2005

1464 Mikael Priks, Optimal Rent Extraction in Pre-Industrial England and France - Default Risk and Monitoring Costs, May 2005

1465 François Ortalo-Magné and Sven Rady, Heterogeneity within Communities: A Stochastic Model with Tenure Choice, May 2005

1466 Jukka Pirttilä and Sanna Tenhunen, Pawns and Queens Revisited: Public Provision of Private Goods when Individuals make Mistakes, May 2005

1467 Ernst Fehr, Susanne Kremhelmer and Klaus M. Schmidt, Fairness and the Optimal Allocation of Ownership Rights, May 2005

1468 Bruno S. Frey, Knight Fever - Towards an Economics of Awards, May 2005

1469 Torberg Falch and Marte Rønning, The Influence of Student Achievement on Teacher Turnover, May 2005

1470 John Komlos and Peter Salamon, The Poverty of Growth with Interdependent Utility Functions, May 2005

1471 Hui Huang, Yi Wang, Yiming Wang, John Whalley and Shunming Zhang, A Trade Model with an Optimal Exchange Rate Motivated by Current Discussion of a Chinese Renminbi Float, May 2005

1472 Helge Holden, Lars Holden and Steinar Holden, Contract Adjustment under Uncertainty, May 2005

1473 Kai A. Konrad, Silent Interests and All-Pay Auctions, May 2005

1474 Ingo Vogelsang, Electricity Transmission Pricing and Performance-Based Regulation, May 2005

1475 Spiros Bougheas and Raymond Riezman, Trade and the Distribution of Human Capital, June 2005

1476 Vesa Kanniainen, Seppo Kari and Jouko Ylä-Liedenpohja, The Start-Up and Growth Stages in Enterprise Formation: The "New View" of Dividend Taxation Reconsidered, June 2005

1477 M. Hashem Pesaran, L. Vanessa Smith and Ron P. Smith, What if the UK had Joined the Euro in 1999? An Empirical Evaluation Using a Global VAR, June 2005

1478 Chang Woon Nam and Doina Maria Radulescu, Effects of Corporate Tax Reforms on SMEs' Investment Decisions under the Particular Consideration of Inflation, June 2005 
1479 Panos Hatzipanayotou, Sajal Lahiri and Michael S. Michael, Globalization, CrossBorder Pollution and Welfare, June 2005

1480 John Whalley, Pitfalls in the Use of Ad valorem Equivalent Representations of the Trade Impacts of Domestic Policies, June 2005

1481 Edward B. Barbier and Michael Rauscher, Trade and Development in a Labor Surplus Economy, June 2005

1482 Harrie A. A. Verbon and Cees A. Withagen, Tradable Emission Permits in a Federal System, June 2005

1483 Hendrik Hakenes and Andreas Irmen, On the Long-Run Evolution of Technological Knowledge, June 2005

1484 Nicolas Schmitt and Antoine Soubeyran, A Simple Model of Brain Circulation, June 2005

1485 Carsten Hefeker, Uncertainty, Wage Setting and Decision Making in a Monetary Union, June 2005

1486 Ondřej Schneider and Jan Zápal, Fiscal Policy in New EU Member States - Go East, Prudent Man!, June 2005

1487 Christian Schultz, Virtual Capacity and Competition, June 2005

1488 Yvan Lengwiler and Elmar Wolfstetter, Bid Rigging - An Analysis of Corruption in Auctions, June 2005

1489 Johannes Becker and Clemens Fuest, Does Germany Collect Revenue from Taxing Capital Income?, June 2005

1490 Axel Dreher and Panu Poutvaara, Student Flows and Migration: An Empirical Analysis, June 2005

1491 Bernd Huber and Marco Runkel, Interregional Redistribution and Budget Institutions under Asymmetric Information, June 2005

1492 Guido Tabellini, Culture and Institutions: Economic Development in the Regions of Europe, July 2005

1493 Kurt R. Brekke and Michael Kuhn, Direct to Consumer Advertising in Pharmaceutical Markets, July 2005

1494 Martín Gonzalez-Eiras and Dirk Niepelt, Sustaining Social Security, July 2005

1495 Alfons J. Weichenrieder, (Why) Do we need Corporate Taxation?, July 2005

1496 Paolo M. Panteghini, S-Based Taxation under Default Risk, July 2005 